\title{
Development of an Accurate Coarse-Grained Model of Poly(acrylic acid) in Explicit Solvents
}

Yaxin An ${ }^{1}$, Samrendra Singh ${ }^{2}$, Karteek K. Bejagam ${ }^{1}$, and Sanket A. Deshmukh ${ }^{* 1}$

1. Department of Chemical Engineering, Virginia Tech, Blacksburg, Virginia 24061, United States

2. CNH Industrial, Burr Ridge, Illinois 60527, United States

Corresponding Author

*sanketad@vt.edu, Phone: +1 540-231-8785

Table S1. The number of all-atom water and DMF molecules in the mixtures of solvents for the study of PAA conformation transition. Note, the number of CG water molecules is half of that of the all-atom water molecules.

\begin{tabular}{|c|c|c|}
\hline $\begin{array}{c}\text { mass fraction of } \\
\text { DMF }(\mathbf{w t} \%)\end{array}$ & $\begin{array}{c}\text { number of all-atom DMF } \\
\text { molecules }\end{array}$ & $\begin{array}{c}\text { number of all-atom water } \\
\text { molecules }\end{array}$ \\
\hline $\mathbf{0}$ & 0 & 10,000 \\
\hline $\mathbf{2 . 6}$ & 100 & 15,000 \\
\hline $\mathbf{1 6 . 8}$ & 500 & 10,000 \\
\hline $\mathbf{3 1 . 1}$ & 1,500 & 13,500 \\
\hline $\mathbf{5 0 . 3}$ & 2,400 & 9,600 \\
\hline $\mathbf{8 0 . 2}$ & 2,500 & 2,500 \\
\hline $\mathbf{1 0 0}$ & 5,000 & 0 \\
\hline
\end{tabular}




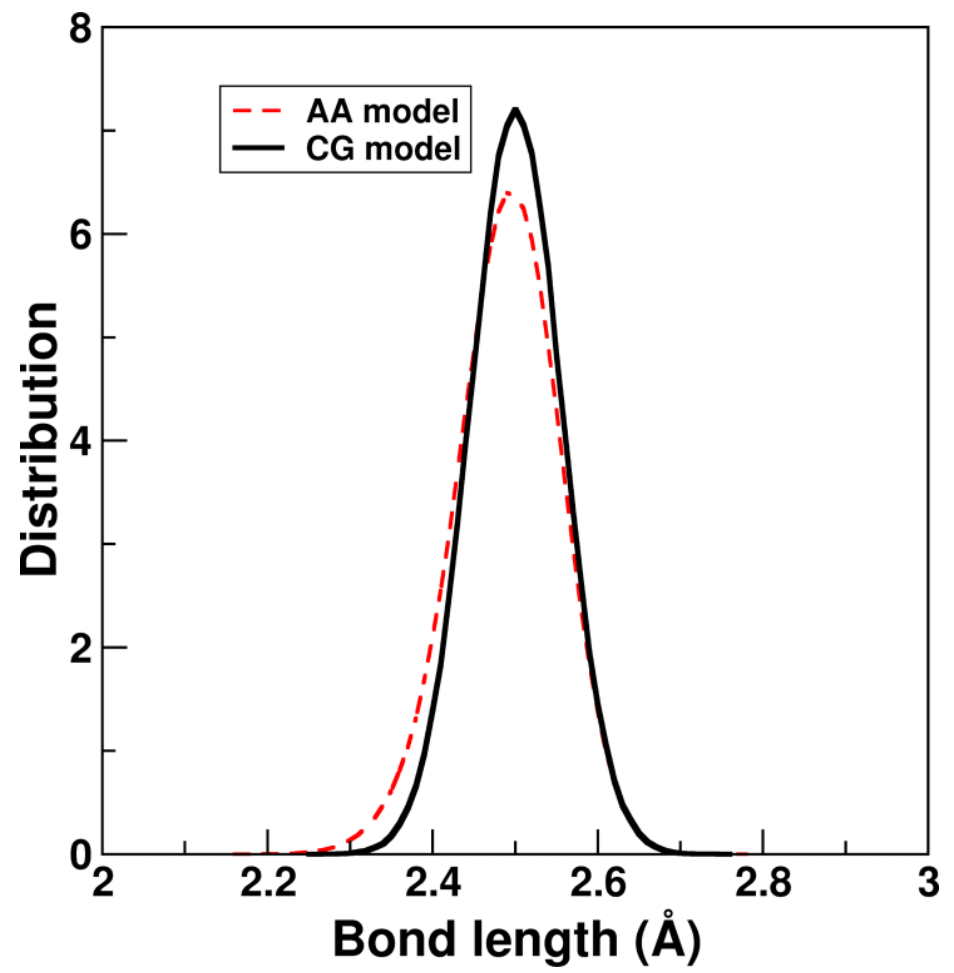

Figure S1. The C2E-COOH bond length distributions for the AA mapped and the CG propionic acid models.

\section{Section S1. Development of the CG Propionic Acid Model by Particle Swarm Optimization S1.1 Force-Field (FF) Optimization}

The following steps were implemented in a particle swarm optimization (PSO) process : (i) a number of parameter sets, for example, $\mathrm{N}$ sets of parameters, were randomly created; (ii) carry out CG MD simulations by using the $\mathrm{N}$ sets of parameters; (iii)analyze the simulation trajectory of each CG MD simulation to obtain the properties of the CG model, like the density and enthalpy of vaporization; (iv) compare the obtained properties of the CG model with those of the reported experimental data, and record the errors from each set of parameters; (v) the set of parameters which showed the least error was called 'locally best', and used to create new $\mathrm{N}$ sets of parameters; (vi) repeat steps iii, iv, and record the set of parameters which showed the smallest errors among all the iterations called 'globally best'; (vii) the PSO was terminated until the errors by using the 'globally best' set parameters was less than tolerance or didn't decrease significantly. A flowchart showing the PSO process is shown in Figure S2. In this work, 80 random sets of parameters of a CG propionic acid including $K_{b}, \varepsilon$, and $\sigma$ values were firstly created, and then CG MD simulations of $500 \mathrm{CG}$ propionic acid molecules were performed at $300 \mathrm{~K}$ with the time-step of $10 \mathrm{fs}$ for $1 \mathrm{~ns}$ to determine the properties of CG propionic acid model, specifically, density, self-diffusion 
coefficient, enthalpy of vaporization, and surface tension. The NAMD simulation package was utilized to perform these simulations by applying periodic boundary conditions in all three directions. ${ }^{1}$ The PSO was iterated until the errors between the properties of CG models and its corresponding experimental values by using the 'globally best' set of parameters didn't decrease significantly. The optimization ranges of the $\mathrm{K}_{\mathrm{b}}, \varepsilon$ and $\sigma$ values are shown in Table S2. The enthalpy of vaporization, the self-diffusion coefficient, the surface tension, and the free energy was obtained by the methods reported in refs ${ }^{2,3}$.

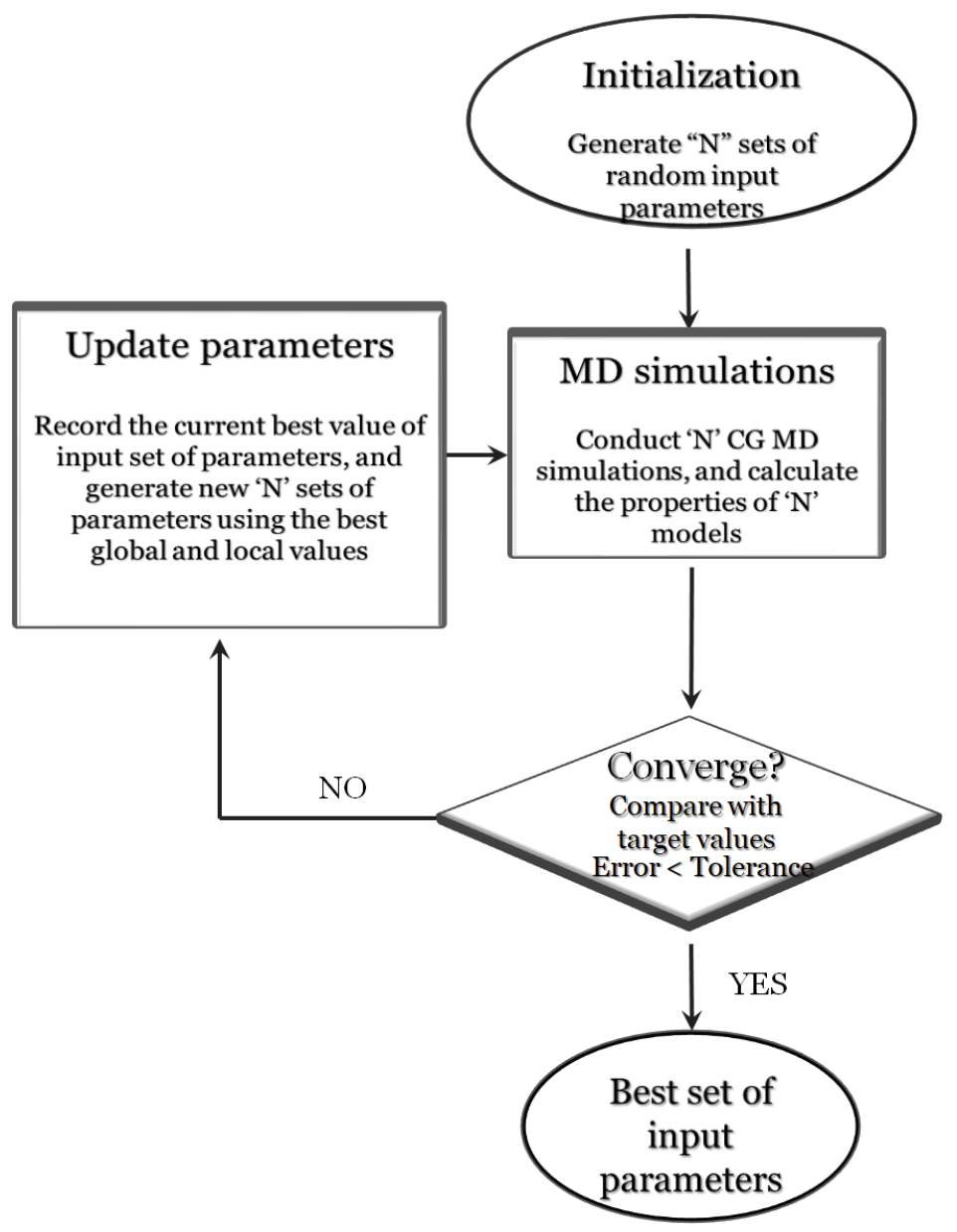

Figure S2. The flowchart of the PSO process in optimizing the CG propionic acid model. 
Table S2. The range of CG FF parameters $\left(r_{\min }-r_{\max }\right)$ and their optimized values. Unit: $\mathrm{K}_{\mathrm{b}}$ - (kcal/ $\left.\mathrm{mol} / \AA^{2}\right), \varepsilon-\mathrm{kcal} / \mathrm{mol}, \sigma-\AA, \mathrm{b}_{0}-\AA$.

\begin{tabular}{|c|c|c|c|}
\hline FF parameter & $\mathbf{r}_{\text {min }}$ & $\mathbf{r}_{\max }$ & Optimized value \\
\hline $\mathrm{K}_{\mathrm{b}}[\mathrm{C} 2 \mathrm{E}-\mathrm{COOH}]$ & 70.0 & 100.0 & 90.98 \\
\hline$\varepsilon[\mathrm{COOH}]$ & 0.30 & 1.60 & 1.2516 \\
\hline$\sigma[\mathrm{COOH}]$ & 2.67 & 5.35 & 3.9356 \\
\hline $\mathrm{b}_{0}[\mathrm{C} 2 \mathrm{E}-\mathrm{COOH}]^{\mathrm{a}}$ & - & - & 2.5 \\
\hline$\varepsilon[\mathrm{C} 2 \mathrm{E}]^{\mathrm{b}}$ & - & - & 0.3710 \\
\hline$\sigma[\mathrm{C} 2 \mathrm{E}]^{\mathrm{b}}$ & - & - & 4.3374 \\
\hline
\end{tabular}

a: estimated from the mapped $\mathrm{COOH}-\mathrm{C} 2 \mathrm{E}$ bond distribution in Figure S1.

b: they were adopted from ref ${ }^{2}$.

\section{S1.2 Structure the CG Propionic Acid Model}

The radial distribution functions (RDFs) of the CG model were compared with those obtained from the AA mapped trajectories. In Figure S3 - (a), the position of the first peak for the CG model was at $\sim 4.6 \AA$, close to that for the AA mapped propionic acid model, $\sim 4.9 \AA$. The first peak in the RDF of the C2E-COOH pair in Figure S3 - (b) was located at $4.5 \AA$, slightly left shifted compared with that of the AA mapped trajectory. A small shoulder at $\sim 3.0 \AA$ in the RDF of $\mathrm{COOH}-\mathrm{COOH}$ obtained from the AA mapped trajectory can be observed in Figure S3 - (c). This shoulder resulted from the formation of hydrogen bonds in AA propionic acid molecules, which were formed between the oxygen in the hydroxyl group and the oxygen attached with carbon atoms by double bonds as the acceptor (see Figure $\mathbf{S 4}$ - (a)). When these hydrogen bonds were formed in AA propionic molecules, the distance between two mapped $\mathrm{COOH}$ bead was measured to be $3.12 \AA$. Besides the shoulder at $\sim 3.0 \AA$, the peak at $\sim 4.1 \AA$ was also caused by hydrogen bonds in AA propionic acid molecules, which is, however, a different type of hydrogen bond. This type of hydrogen bond was formed between the hydroxyl groups of two AA propionic acid molecules (see Figure S4 - (b) of Supporting Information). With the configuration, the distance between the mapped $\mathrm{COOH}$ beads increased to $4.12 \AA$. However, no shoulder was observed in the $\mathrm{RDF}$ of $\mathrm{COOH}-\mathrm{COOH}$ pairs in the CG propionic acid molecules. The first peak was at $4.4 \AA, 0.3$ $\AA$ larger than the position of the first peak in the $\mathrm{RDF}(\mathrm{COOH}-\mathrm{COOH})$ from AA mapped trajectories. The intensity of the first peaks in all the RDFs of bead pairs in the CG model is 
stronger than those of the AA mapped bead pairs, especially for the RDF between the $\mathrm{COOH}-$ $\mathrm{COOH}$ bead pair. This indicates that the interactions between the $\mathrm{CG}$ propionic acids molecules are strong compared with those in AA molecules.
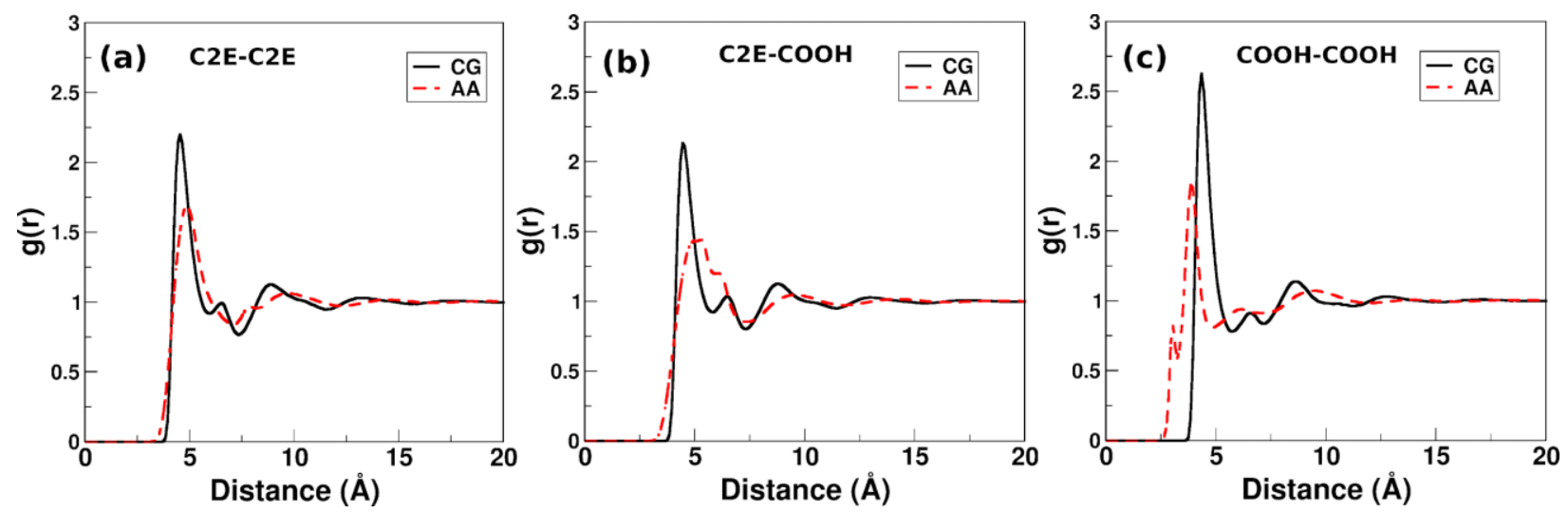

Figure S3. The RDFs between (a) C2E-C2E beads, (b) $\mathrm{C} 2 \mathrm{E}-\mathrm{COOH}$ beads, and (c) $\mathrm{COOH}-\mathrm{COOH}$ beads in the CG propionic acid model (black solid lines) compared with those from the AA mapped trajectories (red dashed lines).
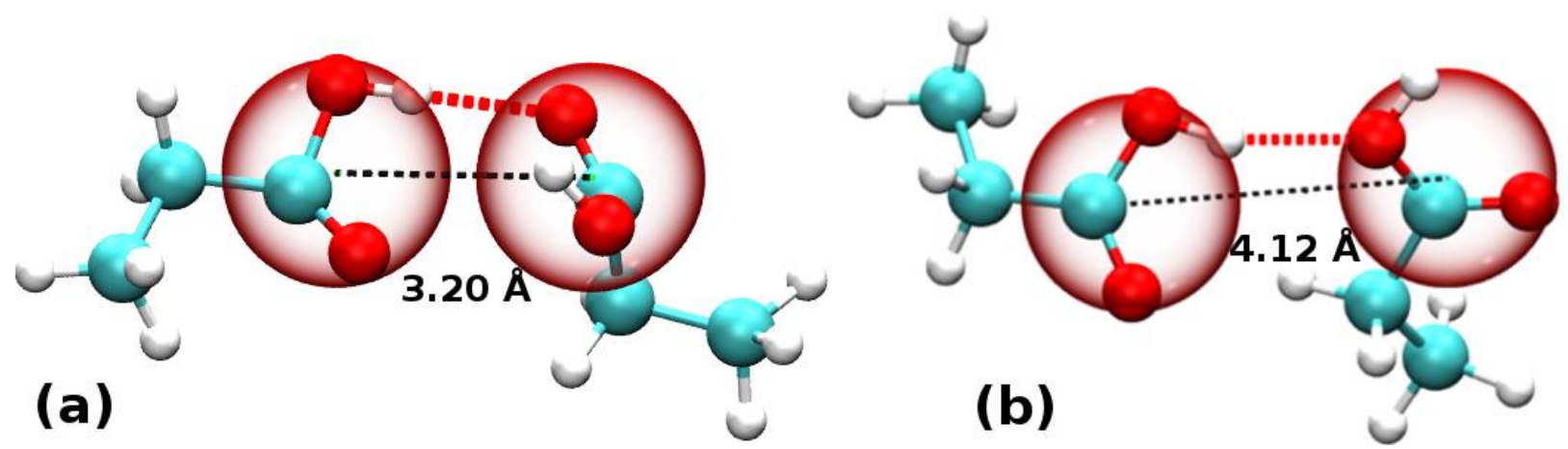

Figure S4: Two types of hydrogen bonds (red dashed lines) which resulted in the different distances (black dashed lines) between mapped $\mathrm{COOH}$ beads (red transparent spheres): (a) 3.20 $\AA$, (b) $4.12 \AA$ A . Oxygen atoms: red filled spheres, hydrogen atoms: white filled spheres, carbon atoms: cyran filled spheres. The criteria for identifying hydrogen bonds is that the donor-acceptor distance is less than $3.5 \AA$ and the acceptor-donor-hydrogen angle is $\leq 30^{\circ} .9$ 
Table S3. The bond FF parameters in the CG PAA model and in the CG DMF model.

\begin{tabular}{|c|c|c|}
\hline bond stretching & $\begin{array}{c}\mathbf{K}_{\mathbf{b}} \\
\left(\mathrm{kcal} /\left(\mathrm{mol} \cdot \AA^{2}\right)\right)\end{array}$ & $\begin{array}{c}\mathbf{b}_{0} \\
(\AA)\end{array}$ \\
\hline $\mathrm{C} 2 \mathrm{E}-\mathrm{C} 2 \mathrm{M}^{\mathrm{a}}$ & 35.29 & 2.56 \\
\hline $\mathrm{C} 2 \mathrm{M}-\mathrm{C} 2 \mathrm{M}^{\mathrm{a}}$ & 36.61 & 2.52 \\
\hline $\mathrm{C} 2 \mathrm{E}-\mathrm{COOH}$ & 90.98 & 2.50 \\
\hline $\mathrm{C} 2 \mathrm{M}-\mathrm{COOH}$ & 90.98 & 2.50 \\
\hline AM-CGD2 & 175.18 & 2.0 \\
\hline
\end{tabular}

a: adopted from ref $^{2}$.

b: adopted from ref ${ }^{10}$.

Table S4. The angle FF parameters in the CG PAA model

\begin{tabular}{|c|c|c|}
\hline bond-angle bending & $\begin{array}{c}\mathbf{K}_{\mathbf{a}} \\
\left(\mathrm{kcal} /\left(\mathrm{mol} \cdot \mathrm{rad}^{2}\right)\right)\end{array}$ & $\begin{array}{c}\text { ao } \\
\left({ }^{\circ}\right)\end{array}$ \\
\hline $\mathrm{C} 2 \mathrm{E}-\mathrm{C} 2 \mathrm{M}-\mathrm{C} 2 \mathrm{M}^{\mathrm{a}}$ & 3.89 & 147.77 \\
\hline $\mathrm{C} 2 \mathrm{M}-\mathrm{C} 2 \mathrm{M}-\mathrm{C} 2 \mathrm{M}^{\mathrm{a}}$ & 3.46 & 144.23 \\
\hline $\mathrm{C} 2 \mathrm{M}-\mathrm{C} 2 \mathrm{E}-\mathrm{COOH}$ & 5.0 & 100.0 \\
\hline $\mathrm{C} 2 \mathrm{M}-\mathrm{C} 2 \mathrm{M}-\mathrm{COOH}$ & 5.0 & 100.0 \\
\hline $\mathrm{C} 2 \mathrm{E}-\mathrm{C} 2 \mathrm{M}-\mathrm{COOH}$ & 5.0 & 100.0 \\
\hline
\end{tabular}

a: adopted from ref ${ }^{2}$.

Table S5. Nonbonded parameters for the CG PAA model and between PAA and CG solvent models: 1-site water and CG DMF

\begin{tabular}{|c|c|c|c|c|c|}
\hline models & $\begin{array}{c}\text { beads or bead } \\
\text { pairs }\end{array}$ & $\begin{array}{c}\boldsymbol{\varepsilon} \\
(\mathbf{k c a l} / \mathbf{m o l})\end{array}$ & $\begin{array}{c}\text { Method used } \\
\text { to obtain } \boldsymbol{\varepsilon} \\
\text { values }\end{array}$ & $\begin{array}{c}\boldsymbol{\sigma} \\
(\mathbf{A})\end{array}$ & $\begin{array}{c}\text { Method } \\
\text { used to } \\
\text { obtain } \boldsymbol{\sigma} \\
\text { values }\end{array}$ \\
\hline $\begin{array}{c}\text { CG hydrocarbon } \\
\text { models }\end{array}$ & $\mathrm{C} 2 \mathrm{E}$ & 0.3710 & ref $^{\mathrm{a}}$ & 4.3374 & ref $^{\mathrm{a}}$ \\
\cline { 2 - 6 } & $\mathrm{C} 2 \mathrm{M}$ & 0.3420 & ref $^{\mathrm{a}}$ & 4.3374 & ref $^{\mathrm{a}}$ \\
\hline 1-site water model & $\mathrm{W} 1$ & 1.1425 & ref $^{\mathrm{b}}$ & 3.772 & ref $^{\mathrm{b}}$ \\
\hline
\end{tabular}




\begin{tabular}{|c|c|c|c|c|c|}
\hline \multirow[t]{2}{*}{ CG DMF model } & $\mathrm{AM}$ & 0.7147 & $\operatorname{ref}^{\mathrm{c}}$ & 3.8908 & $\operatorname{ref}^{\mathrm{c}}$ \\
\hline & CGD2 & 0.3797 & $\operatorname{ref}^{c}$ & 4.5703 & $\operatorname{ref}^{c}$ \\
\hline \multirow[t]{2}{*}{ (1-site water)-DMF } & W1-AM & 0.9036 & Berthelot rule & 3.8314 & $\begin{array}{l}\text { Lorentz } \\
\text { rule }\end{array}$ \\
\hline & W1-CGD2 & 0.6586 & Berthelot rule & 4.1711 & $\begin{array}{l}\text { Lorentz } \\
\text { rule }\end{array}$ \\
\hline $\begin{array}{l}\text { CG propionic acid } \\
\text { model }\end{array}$ & $\mathrm{COOH}$ & 1.2516 & This study & 3.9356 & This study \\
\hline \multirow[t]{3}{*}{ PAA-(1-site water) } & $\mathrm{COOH}-\mathrm{W} 1$ & 1.35 & This study & 3.8538 & $\begin{array}{l}\text { Lorentz } \\
\text { rule }\end{array}$ \\
\hline & C2E-W1 & 0.5130 & $\operatorname{ref}^{d}$ & 3.774 & $\operatorname{ref}^{d}$ \\
\hline & C2M-W1 & 0.440 & $\operatorname{ref}^{d}$ & 3.774 & $\operatorname{ref}^{d}$ \\
\hline \multirow[t]{6}{*}{ PAA-DMF } & $\mathrm{COOH}-\mathrm{AM}$ & 1.35 & This study & $3.9133^{\mathrm{e}}$ & $\begin{array}{l}\text { Lorentz } \\
\text { rule }\end{array}$ \\
\hline & $\mathrm{COOH}-\mathrm{CGD} 2$ & 0.6894 & Berthelot rule & 4.2530 & $\begin{array}{l}\text { Lorentz } \\
\text { rule }\end{array}$ \\
\hline & C2M-AM & 0.4944 & Berthelot rule & 4.1141 & $\begin{array}{l}\text { Lorentz } \\
\text { rule }\end{array}$ \\
\hline & C2E-AM & 0.5149 & Berthelot rule & 4.1141 & $\begin{array}{l}\text { Lorentz } \\
\text { rule }\end{array}$ \\
\hline & C2M-CGD2 & 0.3604 & Berthelot rule & 4.4538 & $\begin{array}{l}\text { Lorentz } \\
\text { rule }\end{array}$ \\
\hline & C2E-CGD2 & 0.3753 & Berthelot rule & 4.4538 & $\begin{array}{l}\text { Lorentz } \\
\text { rule }\end{array}$ \\
\hline
\end{tabular}

a: adopted from ref ${ }^{2}$.

b: adopted from ref ${ }^{3}$.

c: adopted from ref ${ }^{10}$.

$\mathrm{d}$ : adopted from ref ${ }^{11}$. 
Table S6. Properties of the 1 -site water and CG DMF models in ref ${ }^{3,10}$. Experimental data are shown in parentheses at $300 \mathrm{~K}$.

\begin{tabular}{|c|c|c|c|c|}
\hline & $\boldsymbol{\rho}$ & $\mathbf{H}_{\mathbf{v}}$ & $\boldsymbol{\gamma}$ & $\mathbf{D}$ \\
\hline 1-site water & $1.002(0.997)$ & $7.8(10.5)$ & $68.2(72.0)$ & $2.49(2.38)$ \\
\hline CG DMF & $0.943(0.944)$ & - & $33.3(35.8)$ & $1.76(1.63)$ \\
\hline
\end{tabular}

Units: density, $\rho-\mathrm{g} / \mathrm{cm}^{3}$, enthalpy of vaporization, $\mathrm{H}_{\mathrm{v}}-\mathrm{kcal} / \mathrm{mol}$, surface tension, $\gamma-\mathrm{mN} / \mathrm{m}$, selfdiffusion coefficient, $\mathrm{D}-\times 10^{-9} \mathrm{~m}^{2} / \mathrm{s}$.

\section{Section S2. Determination of the Interaction Parameters between PAA and Solvents}

The LJ potential parameters between PAA and solvents were tuned in a systematic way to reproduce the $\mathrm{R}_{\mathrm{g}}$ distributions of the all-atom PAA model in water and DMF. Specifically, to describe the interactions between $\mathrm{W} 1$ beads of water and $\mathrm{COOH}$ beads of PAA, Berthelot combining rule was firstly used to obtain the $\varepsilon[\mathrm{COOH}-\mathrm{W} 1]$ of $1.1958 \mathrm{kcal} / \mathrm{mol}$. The interactions between $\mathrm{C} 2 \mathrm{E} / \mathrm{C} 2 \mathrm{M}$ bead of PAA and $\mathrm{W} 1$ beads were adopted from reference ${ }^{7}$. Then the CG MD simulations of a single PAA chain of 30 -mer in water were performed at $300 \mathrm{~K}$ for $1 \mu \mathrm{s}$. The $\mathrm{R}_{\mathrm{g}}$ distribution of the CG PAA chain was compared with that of the AA model. As can be seen in Figure S5 (a) the $\mathrm{R}_{\mathrm{g}}$ distribution of the $\mathrm{CG}$ model showed a peak at $\sim 7.1 \AA$ as compared to AA model at $\sim 8.8 \AA$. This suggested that the CG chain was in more globule-like state as compared to AA model, implying that the interactions between CG PAA and W1 bead are weak as compared to AA model. Then we manually, systematically increased the interactions between PAA and water by increasing $\varepsilon[\mathrm{COOH}-\mathrm{W} 1]$. The $\varepsilon[\mathrm{COOH}-\mathrm{W} 1]$ of $1.35 \mathrm{kcal} / \mathrm{mol}$, and 1.38 $\mathrm{kcal} / \mathrm{mol}$ showed very good agreement between the $\mathrm{R}_{\mathrm{g}}$ distribution of the CG PAA and that of the all-atom PAA model. However, as the Gibbs hydration free energy of propionic acid in water showed better agreement with $1.35 \mathrm{kcal} / \mathrm{mol}$, we employed these parameters during this study.

To describe the interactions between CG PAA model and DMF, we reproduced the $\mathrm{R}_{\mathrm{g}}$ distribution of the all-atom PAA model in DMF. The interactions between CGD2 and C2E/C2M beads, between CGD2 and $\mathrm{COOH}$ beads, and between $\mathrm{AM}$ and $\mathrm{C} 2 \mathrm{E} / \mathrm{C} 2 \mathrm{M}$ beads were described by the LB combining rules. This is because that the CGD2 bead and C2M/C2E bead are similar, which all represent two carbon atoms and their associated hydrogen atoms. The interaction between $\mathrm{AM}$ and $\mathrm{COOH}$ bead was developed and selected such that we get the best agreement in $\mathrm{R}_{\mathrm{g}}$ distribution of $\mathrm{CG}$ and all-atom model. We initiated the development of $\varepsilon[\mathrm{AM}-\mathrm{COOH}]$ by using 
Berthelot combining rule, which resulted in the initial value of $0.9458 \mathrm{kcal} / \mathrm{mol}$. These results are shown in Figure S5 (b). It can be seen that reasonable agreement with the $\mathrm{R}_{\mathrm{g}}$ distribution of allatom model was obtained when $\varepsilon[\mathrm{AM}-\mathrm{COOH}]$ value was $1.35 \mathrm{kcal} / \mathrm{mol}, 1.38 \mathrm{kcal} / \mathrm{mol}$, and 1.4 $\mathrm{kcal} / \mathrm{mol}$. The Gibbs free energy values for the monomer analogue of PAA, propionic acid by using the $\varepsilon[\mathrm{AM}-\mathrm{COOH}]$ value of $1.35,1.38$, and $1.4 \mathrm{kcal} / \mathrm{mol}$ were $-9.4,-9.9$, and $-9.9 \mathrm{kcal} / \mathrm{mol}$, respectively. As the Gibbs free energy for the all-atom propionic acid model in DMF is -7.4 $\mathrm{kcal} / \mathrm{mol}$, we decided to use $1.35 \mathrm{kcal} / \mathrm{mol}$ in this research.
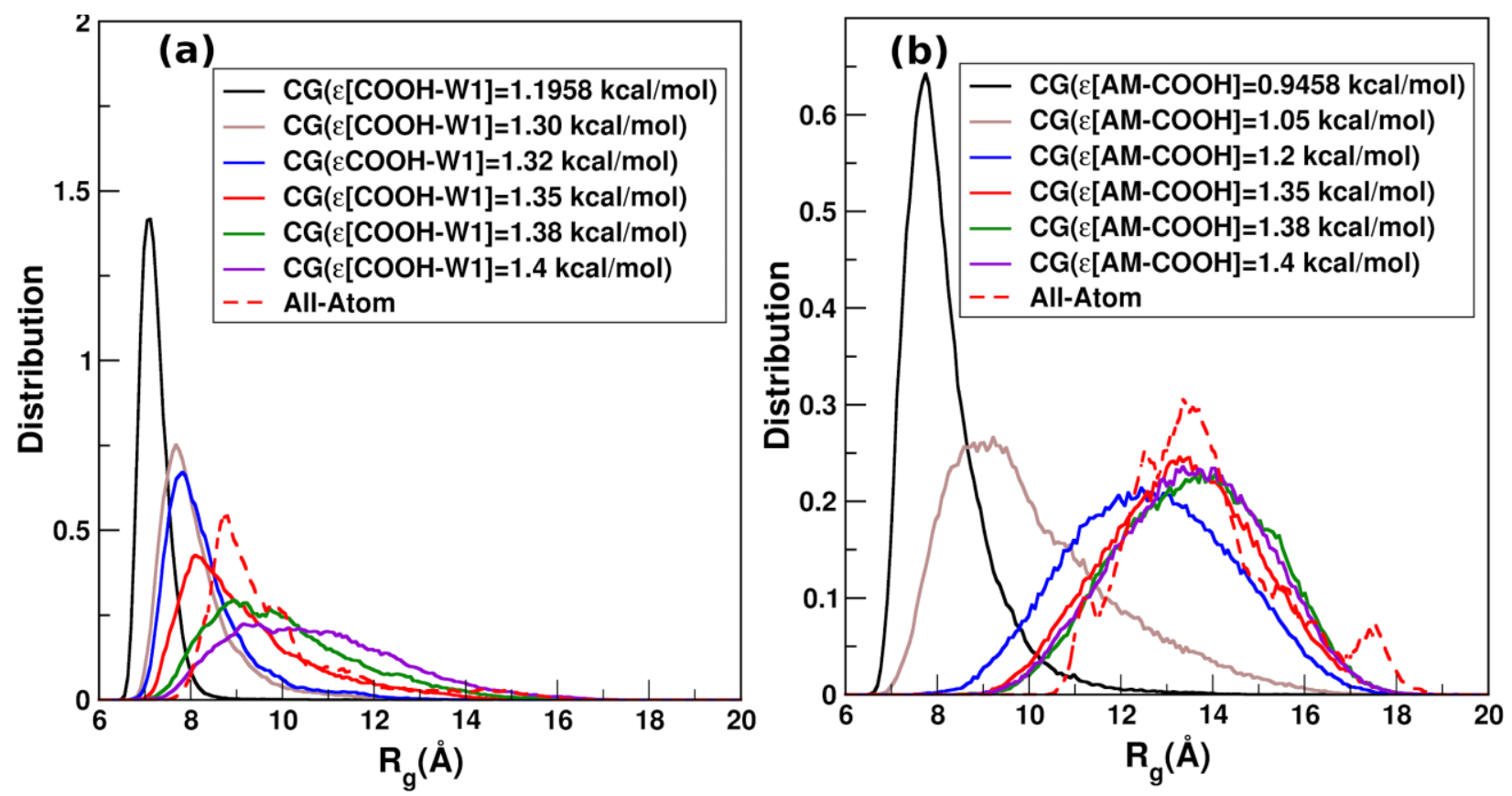

Figure S5. The $\mathrm{R}_{\mathrm{g}}$ distributions of the CG PAA model in (a) water and (b) DMF with different $\varepsilon$ values.

\section{Section S3. Method to Determine the Gibbs Free Energies:}

The adaptive biasing force (ABF) method implemented in colvars package was employed to calculate the Gibbs solvation and hydration free energies of AA and CG models in DMF and water. For example, consider the case of determining the Gibbs hydration free energy of CG propionic acid. A schematic showing the initial structure of ABF simulations is in Figure S6. The simulation box of water bulk with size $39 \AA$ x $39 \AA$ x $39 \AA$ contains 1000 CG 1-site water molecules. A propionic acid molecule is placed at a distance of $35 \AA$ to the center of mass (COM) of the water bulk in the Z-direction. The air/water interface was created by extending the Zdirection to $100 \AA$. NVT ensemble simulations were performed with the periodic boundary 
conditions in all three directions. Reaction coordinate (RC) was defined as the distance between the COM of the water box and that of the propionic acid molecule projected to the Z-direction. 'DistanceZ' style of colvars module was utilized to perform these free energy simulations. The profile of Gibbs hydration or solvation free energy was obtained along the RC varying from $0 \AA$ (center of bulk water or DMF) to $35 \AA$ (vacuum). Entire RC was divided into smaller bins of 0.2 $\AA$ for the accumulation of force experienced on the RC and later it is averaged out for 500 force samples ( $F_{\text {avg }}$ ). ABF applies an equal and opposite force along the entire RC to nullify the force experienced on the $\mathrm{RC}$ and continues to apply the force so as to smoothen the energy surface for uniform sampling. A final production run of $100 \mathrm{~ns}$ was performed with a timestep of $5 \mathrm{fs}$ at 300 K. Similar approach was used to calculate the Gibbs hydration free energies of AA and CG DMF molecules, the Gibbs solvation free energy of the CG propionic acid model in this study.

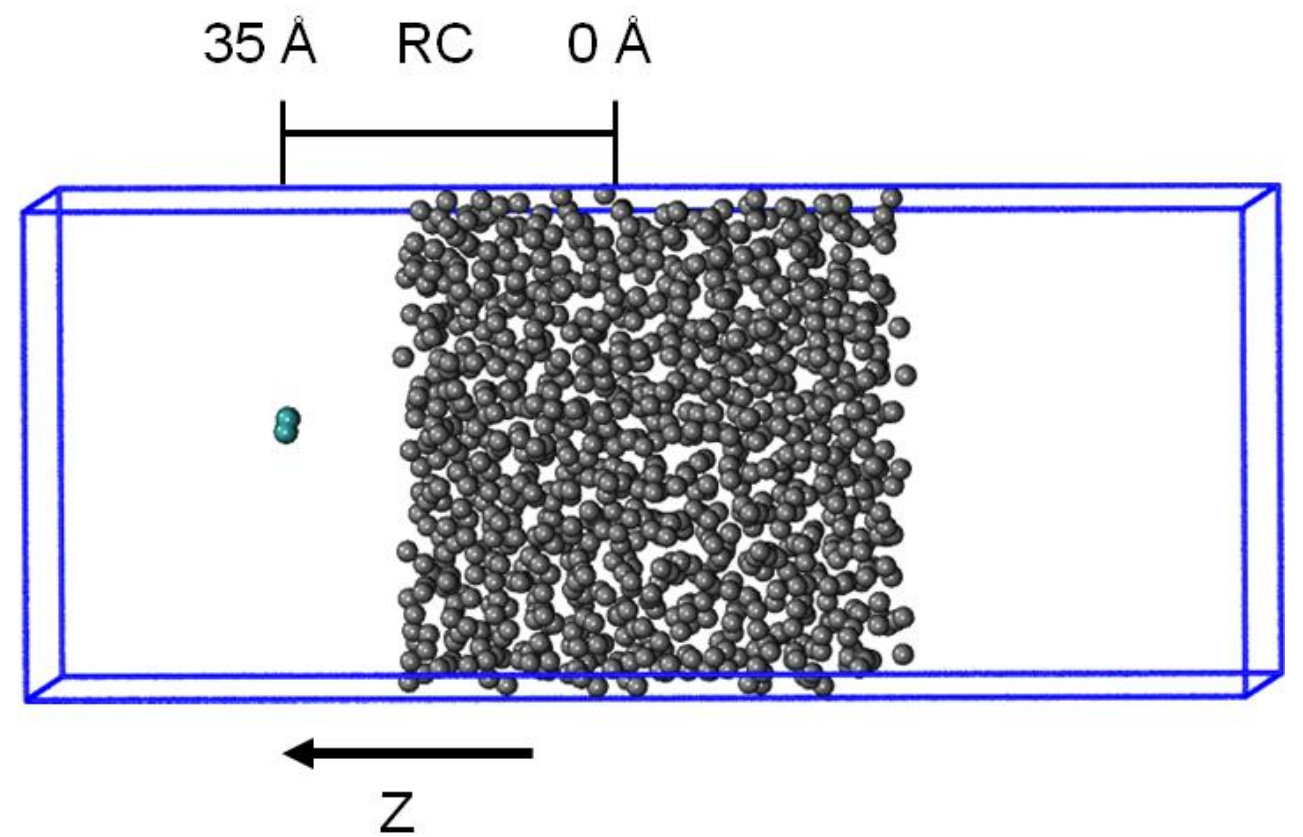

Figure S6. The schematic of ABF simulations to calculate the Gibbs hydration free energy of the CG propionic acid model. Cyan sphere: a CG propionic acid molecule, gray spheres: 1-site water molecules. 


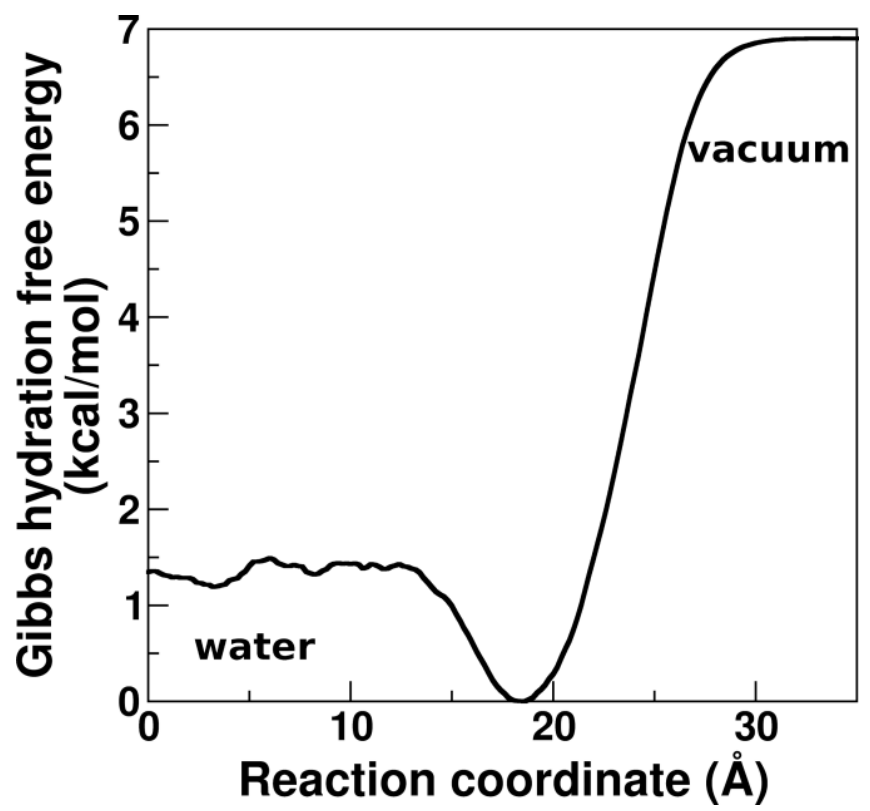

Figure S7. The Gibbs hydration free energy profile of one CG DMF molecule when pulled into 1-site water bulk.
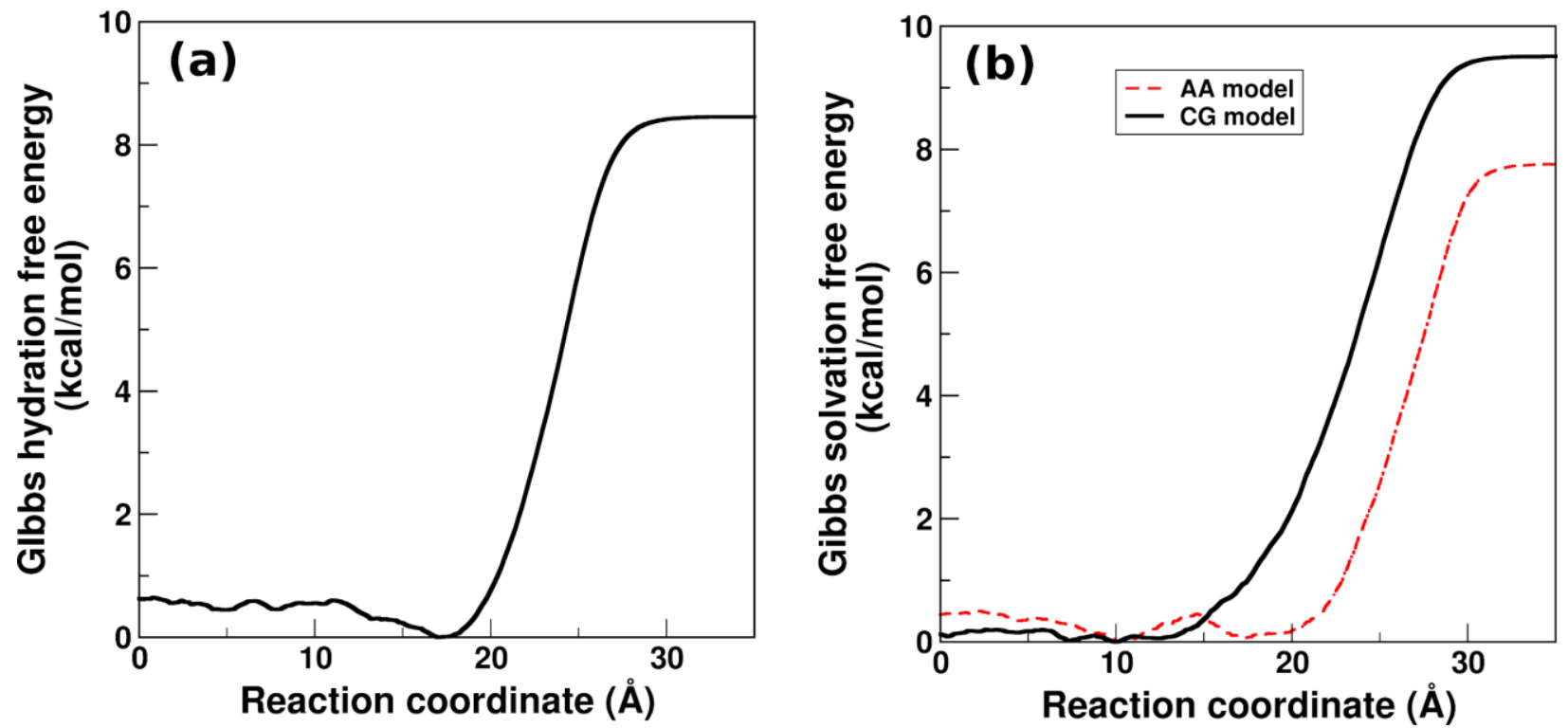

Figure S8. The profiles of (a) Gibbs hydration free energy of the CG propionic acid in water and (b) Gibbs solvation free energy of AA and CG propionic acid models in DMF at $300 \mathrm{~K}$. 
Table S7. The compositions of the solvent mixtures of CG 1-site water and DMF models.

\begin{tabular}{|c|c|c|}
\hline mass fraction of DMF & $\begin{array}{c}\text { number of CG DMF } \\
\text { molecules }\end{array}$ & number of CG 1-site water \\
\hline $\mathbf{0}$ & 0 & 5000 \\
\hline $\mathbf{0 . 1 0 1 1}$ & 250 & 4507 \\
\hline $\mathbf{0 . 2 9 0 7}$ & 100 & 495 \\
\hline $\mathbf{0 . 4 4 2 9}$ & 250 & 638 \\
\hline $\mathbf{0 . 6 5 8 2}$ & 250 & 263 \\
\hline $\mathbf{0 . 8 2 4 0}$ & 500 & 216 \\
\hline $\mathbf{0 . 9 2 3 5}$ & 500 & 84 \\
\hline $\mathbf{1 . 0}$ & 10000 & 0 \\
\hline
\end{tabular}

\section{Section S4. Sampling Quality of All-Atom PAA and Pure Solvent Simulations:}

Although MD simulations have emerged as an important tool to study macromolecule systems with millions of atoms, on many occasions its application is limited due to insufficient sampling. Primary cause of this insufficient sampling is the rough energy landscapes, which has many local minima separated by high-energy barriers that controls the motion of macromolecules. $^{23}$

There are a number of analysis methods such as root mean square deviation (RMSD), cluster counting, principal component analysis (PCA) that can provide qualitative insights on the overall sampling effectiveness. ${ }^{26}$ In general, they can suggest if the simulation time is too short to sample the space. RMSD is one such simple tool which is often used to evaluate the sampling effectiveness. RMSD compares the initial structure of a macromolecule to that throughout the trajectory via a distance measure ${ }^{26}$ Here, we have computed the RMSD of PAA chain in pure water, and pure DMF using Eq. S1.

$$
\boldsymbol{R M S D}=\sqrt{\frac{\sum_{i=0}^{N}\left[m_{i}^{*}\left(X_{i}-Y_{i}\right)^{2}\right]}{M}}
$$

Where $\mathrm{N}$ is the total number of atoms, $\mathrm{m}_{\mathrm{i}}$ is the mass of atom $i, \mathrm{X}_{\mathrm{i}}$ is the coordinate vector for target atom $i, \mathrm{Y}_{\mathrm{i}}$ is the coordinate vector for reference atom $i$, and $\mathrm{M}$ is the total mass. 
In the initial $10 \mathrm{~ns}$ a rapid rise in the RMSD is observed due to thermal fluctuations (see Figure S9). This is followed by fluctuations in the RMSD around its mean value of $\sim 12.8 \AA$ and $\sim 8.9 \AA$ in water and DMF, respectively. The overall fluctuations in the mean value for both water and DMF decrease after $\sim 150 \mathrm{~ns}$. The RMSD plots suggest that both systems have reached steady state and polymer conformation has equilibrated.

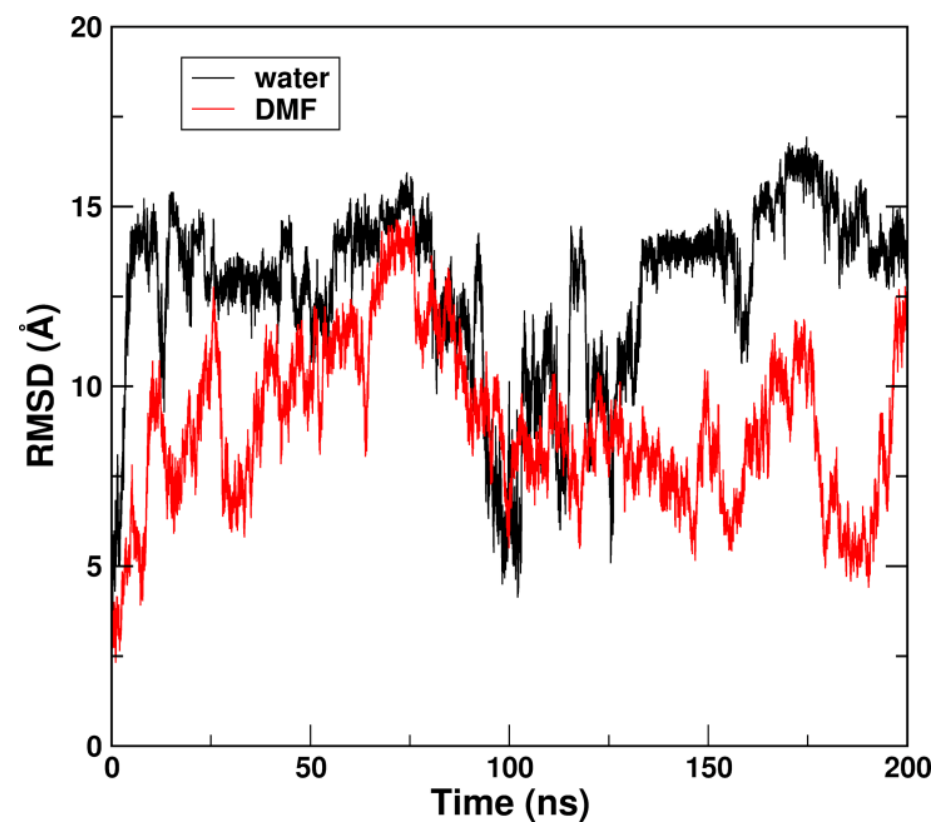

Figure S9. The RMSD of the all-atom PAA model in pure water and pure DMF.

To further extract the large scale characteristic motions of PAA chain, PCA was used. ${ }^{27}$ The first step in PCA is the building of the $3 n \times 3 n$ fluctuation correlation matrix (C), where $n$ is the number of atoms in a system: ${ }^{26}$

$$
c_{i j}=<x_{i}-\bar{x}_{\imath}><x_{j}-\overline{x_{j}}>
$$

Where $\mathrm{x}_{\mathrm{i}}$ represents a specific degree of freedom and overbar depict the average structure.

The cartesian coordinates of the heavy atoms in PAA (carbon and oxygen), stored every $100 \mathrm{ps}$, were utilized to perform the PCA analysis. The matrix was used to reproduce eigenvalues (the mean square fluctuations along its corresponding vector), and eigenvectors (characteristic motions for the system). PCA reveals existence of a number of sub-states for a given macromolecule in a simulation trajectory. In general, a well-sampled simulation exhibits a large 
number of transitions among substates. The first two principal components for PAA in water and DMF is shown in Figure S10 (a) and (b), respectively. In Figure S10, clustering of data can be observed for PAA both in water and DMF, which suggest that PAA exhibits several sub-states. For example, in water, although the $\mathrm{R}_{\mathrm{g}}$ values of the PAA chains are similar, $\sim 8 \AA$, clustering of data points in different regions suggests the presence of different conformations with similar values of $\mathrm{R}_{\mathrm{g}}$. In pure DMF less number of sub-states were exhibited by the PAA chain as compared to water.
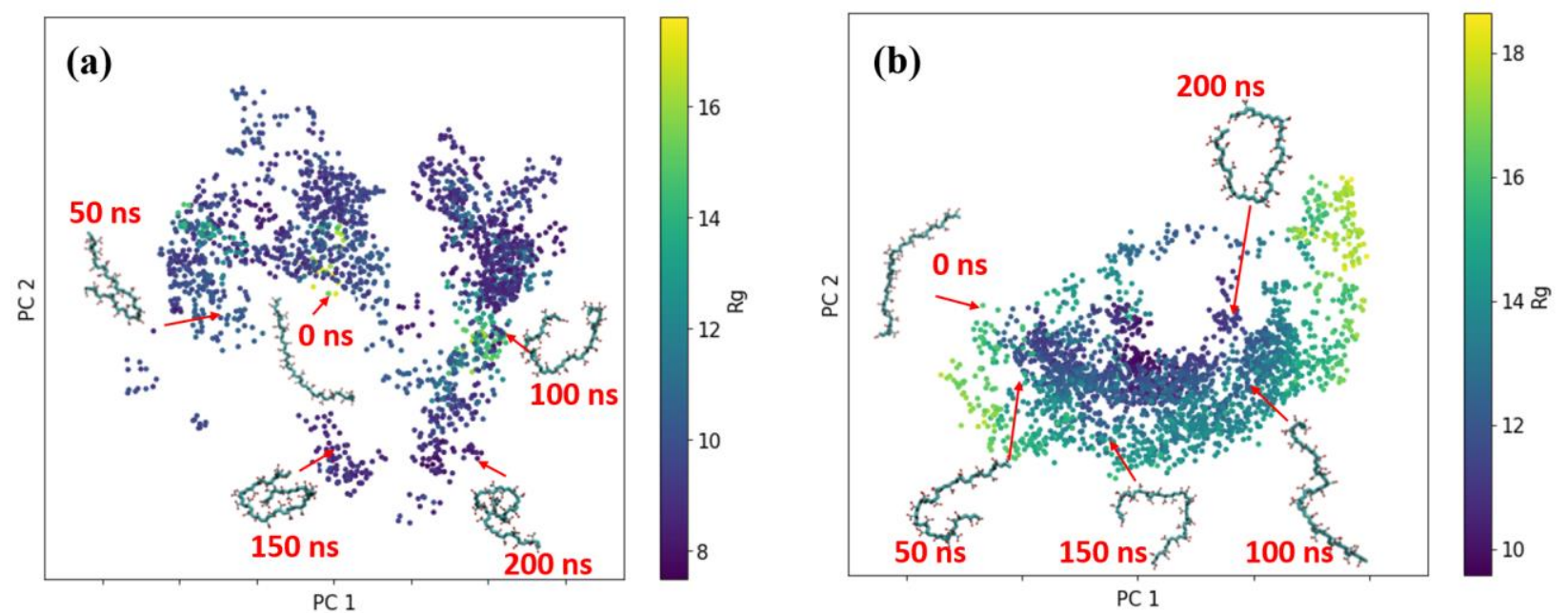

Figure S10. Projection of the transient structures of the all-atom PAA model on the principle plane spanned by the two most significant components (PC1 and PC2) obtained by analyzing the cartesian coordinates of the all-atom PAA model in (a) water and (b) DMF. 


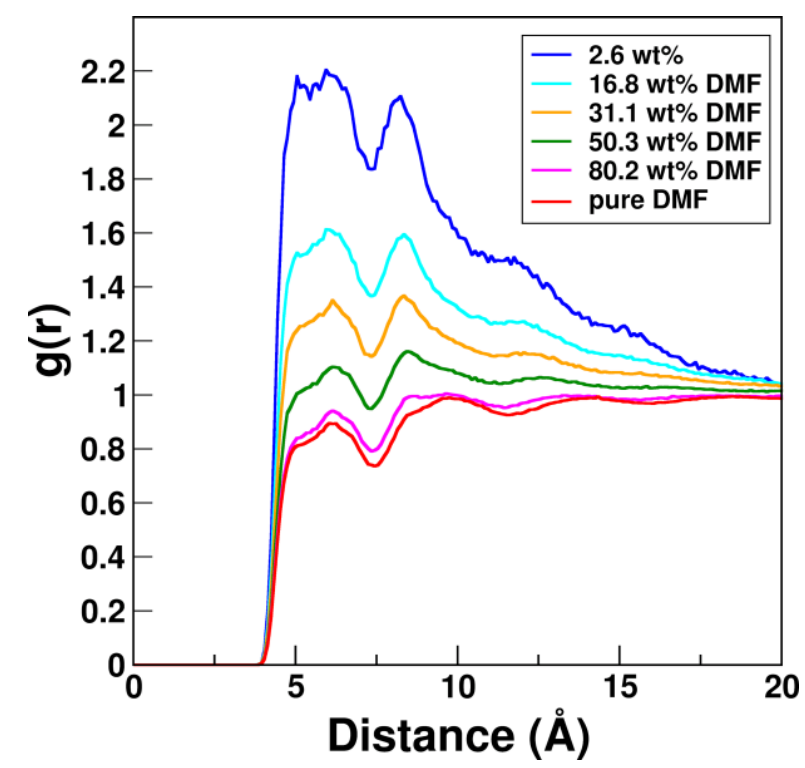

Figure S11. The RDF between CGD2 bead in DMF and C2M beads in the backbone of PAA

Table S8. The coordination number of CGD2 beads around the C2M beads at a cutoff of $7.25 \AA$ (the position of the first valley in Figure S10).

\begin{tabular}{|c|c|}
\hline solvent bulk & number of CGD2 beads \\
\hline pure water & 0 \\
\hline $\mathbf{2 . 6} \mathbf{w t} \%$ DMF & 0.57 \\
\hline $\mathbf{1 6 . 8} \mathbf{w t} \%$ DMF & 2.64 \\
\hline $\mathbf{3 1 . 0} \mathbf{w t} \%$ DMF & 4.0 \\
\hline $\mathbf{5 0 . 3} \mathbf{w t} \%$ DMF & 5.28 \\
\hline $\mathbf{8 0 . 2} \mathbf{w t} \%$ DMF & 6.94 \\
\hline pure DMF & 8.17 \\
\hline
\end{tabular}

\section{References}

(1) Phillips, J. C.; Braun, R.; Wang, W.; Gumbart, J.; Tajkhorshid, E.; Villa, E.; Chipot, C.; Skeel, R. D.; Kalé, L.; Schulten, K. Scalable Molecular Dynamics with NAMD. J. Comput. Chem. 2005, 26 (16), 1781-1802.

(2) An, Y.; Bejagam, K. K.; Deshmukh, S. A. Development of New Transferable CoarseGrained Models of Hydrocarbons. J. Phys. Chem. B 2018, 122 (28), 7143-7153. 
(3) Bejagam, K. K.; Singh, S.; An, Y.; Berry, C.; Deshmukh, S. A. PSO-Assisted Development of New Transferable Coarse-Grained Water Models. J. Phys. Chem. B 2018, 122, 19581971.

(4) Allison, J. R.; Riniker, S.; van Gunsteren, W. F. Coarse-Grained Models for the Solvents Dimethyl Sulfoxide, Chloroform, and Methanol. J. Chem. Phys. 2012, 136 (5), 054505.

(5) Yesylevskyy, S. O.; Schäfer, L. V.; Sengupta, D.; Marrink, S. J. Polarizable Water Model for the Coarse-Grained MARTINI Force Field. PLoS Comput. Biol. 2010, 6 (6), e1000810.

(6) Bender, H. J.; Hertz, H. G. Model Orientation Dependent Pair Distribution Functions in Three Dimensions for the Liquid Mixtures of Propionic Acid and of Ethanol with Carbon Tetrachloride. Berichte der Bunsengesellschaft für physikalische Chemie 1977, 81 (5), 468478.

(7) Subha, M. C. S.; Rao, S. B. Densities and Viscosities of Propionic Acid in Benzene, Methylbenzene, Ethylbenzene, and Propylbenzene. J. Chem. Eng. Data 1988, 33 (4), 404 406.

(8) Ahluwalia, R.; Gupta, R.; Vashisht, J. L.; Wanchoo, R. K. Physical Properties of Binary Liquid Systems: Ethanoic Acid/Propanoic Acid/Butanoic Acid with Cresols. J. Solution Chem. 2013, 42 (5), 945-966.

(9) de Oliveira, T. E.; Mukherji, D.; Kremer, K.; Netz, P. A. Effects of Stereochemistry and Copolymerization on the LCST of PNIPAm. J. Chem. Phys. 2017, 146 (3), 034904.

(10) Bejagam, K. K.; Singh, S.; An, Y.; Deshmukh, S. A. Machine-Learned Coarse-Grained Models. J. Phys. Chem. Lett. 2018, 4667-4672.

(11) An, Y.; Bejagam, K. K.; Deshmukh, S. A. Development of Transferable Nonbonded Interactions between Coarse-Grained Hydrocarbon and Water Models. J. Phys. Chem. B 2019, 123 (4), 909-921. 